\title{
VARIACIONES SOBRE LA PINTURA INGLESA EN LA NARRATIVA DE MARGO GLANTZ
}

\author{
Adriana Kanzepolsky \\ Universidade de São Paulo \\ adrianakanze@gmail.com
}

Resumen: Nuestro trabajo analiza el diálogo que en Saña, Historia de una mujer que caminó por la vida con zapatos de diseñador y Por breve herida de Margo Glantz se establece entre el discurso de la pintura y el discurso de la literatura, centrándonos particularmente en la figura y las pinturas de Francis Bacon. Leemos esta relación en dos niveles: concebimos la narrativa de Glantz como una textualidad que se abre a las voces de otros -los pintores, en este caso-, donde no hay preeminencia de un discurso sobre otro, y entendemos las pinturas, en especial, los retratos de Inocencio $\mathrm{X}$ de Bacon, como una variación del cuadro de Velázquez u otras, que funcionan como un eco de cuadros de Picasso, en tanto un discurso que construye una poética similar a la que organiza los textos de la escritora mexicana. Nos referimos puntualmente a la cita, la autocita, la variación y el dislocamiento de fragmentos.

Palabras clave: Margo Glantz, Francis Bacon, Pintura, Por breve berida, Saña, Historia de una mujer que caminó por la vida con zapatos de diseñador

\begin{abstract}
This paper analyses the dialogue between the discourse on painting and the discourse on literature in Saña, Historia de una mujer que caminó por la vida con zapatos de diseñador y Por breve herida, by Margo Glantz, focusing on Francis Bacon and his paintings. We read this relation in two levels: by comprehending Glantz's narrative as a textuality that opens up to the voices of others - painters, in this case - where there is no pre-eminence of one discourse above other, and by considering, in particular, Bacon's Inocencio $\mathrm{X}$ portraits as variation of Velázquez's painting or others, which produce an echo of Picasso's paintings, as a discourse that set up a poetics similar to the one that organizes the texts of the Mexican writer. We punctually allude to the quotation, the self-quotation, the variation, and the dislocation of fragments.
\end{abstract}

Keywords: Margo Glantz, Francis Bacon, Painting, Por breve berida, Saña, Historia de una mujer que caminó por la vida con zapatos de diseñador 
En "Una historia de amor", uno de los relatos que integran Historia de una mujer que caminó por la vida con zapatos de diseñador, Margo Glantz afirma:

[...] mi texto apenas alcanza el nivel de un cromo o de un paisaje de acuarela, acercamiento superficial, es decir pintoresco, aunque quisiera tener la misma calidad de ese tipo de pintura llamada así, pintoresca, de la cual se dice (¿apropiadamente?) que era representante Turner (no lo creo), Turner, el pintor inglés que más me atrae junto a Stanley Spencer, Francis Bacon y Lucien Freud (Glantz, 2005, p. 98).

El fragmento lleva a cabo varias operaciones: valora su propia escritura en tanto la pone en relación con otro sistema, el de la pintura, en este caso la inglesa, cuyo nivel de calidad se desea y, dentro de la misma, afirma una predilección que se organiza sobre un conjunto de nombres que reaparecerán insistentemente en otros textos dando forma a una suerte de tradición. Turner, Stanley Spencer, Francis Bacon y Lucien Freud, a los que en menor medida cabría agregar Grünewald, ajeno a la tradición inglesa pero cuyas crucifixiones en las que pinta el dolor de Cristo como un dolor físico, es decir, como dolor de un cuerpo, la atraen y perturban, son los pintores a los que una y otra vez vuelve en textos como Saña (2010), Historia de una mujer (2005) y Por breve herida (2016). Un libro, este último, en el que la figura, las declaraciones y las pinturas de Bacon, una de las cuales ilustra la tapa, son inescindibles de la lógica tanto temática como formal del mismo, a un grado tal que sitúa en los cuadros del inglés su punto de partida. Es así que en uno de los fragmentos en los que se detiene sobre su propia escritura leemos: "Varios de los textos se recogerán, se alterarán, se reconstruirán y formarán parte de esta textualidad, cuyo punto 
de partida son los dientes y también, las pinturas de Francis Bacon" (Glantz, 2016, p. 161).

La reiteración de estos nombres, en particular los de Bacon y Spencer, que a veces reencontramos en la reproducción de pasajes idénticos de otros textos, en los que la escritora se detiene en la interpretación de su pintura, o en ocasiones, en los que vuelve a narrar episodios biográficos de los mismos, o aún, en la repetición de párrafos que reescriben o citan declaraciones de dichos artistas en entrevistas o documentales que protagonizaron, se inscribe en y reduplica la lógica que articula la poética de la escritora mexicana. Una poética en la que, como se sabe, abundan las autocitas, los dislocamientos de fragmentos, cuyo sentido se altera de un texto a otro (según declara repetidamente). Una textualidad que se organiza sobre las variaciones de lo ya escrito, sobre el tránsito entre la ficción, el ensayo y la autobiografía y, en la que muchas veces, explicita los procedimientos y la lógica de sus elecciones. Sin embargo, cuando nos detenemos en los nombres que aquí reitera, en particular el de Francis Bacon, vemos que el juego entre repetición y variación se potencia, ya que no estamos ante un procedimiento exclusivo de Glantz sino nodal también para la lógica que articula la poética del pintor o, por lo menos, los aspectos de esta obra que Margo Glantz recorta y en los que su mirada y su escritura se focalizan. Me refiero puntualmente a los retratos del Papa Inocencio $\mathrm{X}$, variaciones del cuadro de Velázquez y, sobre todo, a la pintura de su boca o del horror encerrado en esa boca.

Si bien la mayor parte de las pinturas en las que la letra de Glantz escarba son las que integran la serie de retratos del Papa, 
en diversos momentos sus especulaciones giran, con un grado de deslumbramiento y obsesión casi idénticos, alrededor de los cuadros de Bacon que remiten a Picasso, en particular, al Picasso que retrata a las bañistas a finales de la década del '20 y, en una u otra ocasión, a la versión de La Maja de Goya pintada por el inglés. Se trata siempre de pinturas que representan la figura humana, ante las cuales el análisis de Glantz apunta a la repetición y la variación que opera Bacon en el diálogo que establece con los pintores que lo precedieron.

Aunque en ese juego de pentimentos (simbólicos y literales) las pinturas de Bacon remiten a Velázquez y Picasso -como señalamos-, Glantz especula y afirma que es Stanley Spencer, cuya visión del cuerpo aniquila la concepción victoriana del mismo, el pintor que posibilita el tipo de representación desarrollada por Francis Bacon, pero también por Lucien Freud. Una visión del cuerpo humano que la escritora califica como peligrosamente cercana a "una animalidad de matadero" (Glantz, 2010, p. 223). Explícitamente sentencia:

[...] Stanley anticipa a Bacon: si Spencer no hubiera pintado como lo hizo, Bacon jamás habría sido el tipo de pintor que fue y definitivamente estoy totalmente segura, Lucien Freud tampoco (Glantz, 2005, p. 55).

Estamos, entonces, ante una serie de textos, cada uno de los cuales puede leerse de forma autónoma, pero que simultáneamente reenvían al conjunto o a la totalidad de lo ya escrito. Como dijimos, textos organizados sobre la repetición y la variación, dos procedimientos que exceden el libro concebido como una unidad de sentido y se diseminan y expanden entre libros diversos, entre libros de géneros diferentes, o incluso, 
entre géneros diferentes dentro de un mismo libro. Es decir, muchas veces los fragmentos reaparecen pero sometidos a las leyes de otro género, algo que se evidencia particularmente en la relación entre Saña, un conjunto de ensayos breves, e Historia de una mujer..., donde el sujeto de la enunciación es un personaje ficcional que protagoniza diversos episodios biográficos.

Ahora, si cada uno de los libros de Glantz se cierra y no se cierra sobre sí mismo y se define por una inestabilidad genérica que les es constitutiva, también cada uno de ellos, y es lo que nos interesa ahora, se abre a las voces de otros (los pintores en este caso, pero también otros escritores), cede la palabra a otros, confundiéndola por momentos con su propia voz; una operación en la que claramente se diluye la autoría. Pero no se trata solamente de escribir con otros sin establecer una preeminencia de las voces, sino también, en los libros a los que nos referimos, de poner en diálogo el discurso de la literatura con el discurso de/sobre la pintura, un diálogo en el que tampoco plantea la preeminencia de una disciplina sobre otra. Es decir, confluyen voces, géneros, discursividades diversas, materiales heterogéneos que incorpora sin ningún tipo de privilegio o jerarquización.

A diferencia de muchos otros libros de autores contemporáneos los textos de Glantz no incorporan materiales extra literarios, y en ese sentido no pueden pensarse como textos inscriptos en lo que se denomina un arte multimedia. Me refiero específicamente a libros que incorporan imágenes, sobre todo fotografías pero no únicamente; un material fundamental que posibilita pensarlos como un "arte inespecífico" (Garramuño, 2015, p. 158) o "fuera de sí" -como lo denomina Florencia 
Garramuño (Garramuño, 2015, p. 184) -, cuya incorporación cuestionaría la preeminencia de la literatura sobre otras formas de discurso artístico. Sin embargo, aunque circunscripta estrictamente al ámbito de la palabra, pienso que la literatura de Glantz no sólo se inscribe dentro de este arte inespecífico, de una identidad "resbaladiza y ambigua" -para usar sus propias palabras cuando se refiere a Bacon- sino que esta escritora viene desarrollando ese tipo de propuesta desde hace varias décadas, en la que se evidencian "perforaciones" y desestabilizaciones de categorías (Garramuño), como también un cruce entre realidad y ficción. ${ }^{1}$

Si pensamos en la ya extensa producción de Glantz a lo largo de las cuatro últimas décadas, diría que su obra no sólo se inscribe en esta problemática tan en boga en este momento, sino que la escritora mexicana es una pionera dentro del continente y por lo mismo su literatura demoró tanto tiempo en ser acogida y reconocida.

Por otra parte, poner en escena las voces de otros por medio de esa remisión a las palabras de los pintores en entrevistas o documentales sobre sus vidas y sus elecciones estéticas, a los que nos referimos antes, también constituye un modo de descentramiento de la propia autoría y de la literatura en sí, e introduciría en este discurso -y otra vez dialogo con

\footnotetext{
${ }^{1}$ En este sentido, me pregunto si extremando el razonamiento no sería posible pensar que la repetición constante de expresiones o fragmentos en el interior de un mismo libro no los convierte en una suerte de estribillos, esa figura clave del poema y, en consecuencia, la misma funcionaría como un elemento más que hace a la inespecificidad del texto y potencia su inscripción en las formas de arte contemporáneo.
} 
Garramuño- un gesto político, en el sentido de hacer del texto literario un espacio común.

Creo que en este punto cabría hacerse algunas preguntas: ¿qué le dicen las artes plásticas a esta escritora o por qué el discurso de y sobre la pintura insiste en sus textos? Hablo específicamente de la pintura de dos o tres artistas ingleses del siglo XX. Y, junto con ello: ¿de qué manera, a través de cuáles procedimientos la prosa de Glantz se apropia de la pintura de Bacon y de Stanley Spencer? ¿Cómo se ponen en relación esos discursos y cuál es la función que les cabe dentro de los textos de Margo Glantz?

Para tratar de responder a estas preguntas, pienso que habría que detenerse primero en el lugar que ocupa el sujeto de la enunciación -ya se trate de Glantz, en el caso de los ensayos, ya de Nora García, en el de los cuentos- cuando especula sobre la pintura. En principio, lo que tenemos es un sujeto que mira, que mira lo que los otros han mirado, han visto, y que construye una especulación a partir de esta mirada; un sujeto que ensaya, que reflexiona. Ensaya con la inteligencia y a la vez reconstruye los efectos que sobre su cuerpo producen algunas de estas pinturas.

En segundo lugar, estamos ante alguien que recupera escenas, pasajes de la vida de estos pintores, es decir, que pone en relación arte y vida. Por un lado, porque los propios pintores ya lo hicieron, como se lee en las palabras de Stanley Spencer que cita: "Por lo general [...] cuando trato de entender el significado de una de mis pinturas, me siento frente a ella y me preparo a oír la historia de mi propia vida" (Glantz, 2010, p. 72). Por otra parte, porque es la forma en que ella opera en y con su literatura, 
donde su vida se convierte en materia de escritura pero donde también el arte es materia de su vida, es decir, se presentan como órdenes intercambiables o casi.

$\mathrm{Y}$ en ese orden de la relación entre vida y literatura, la narradora de los cuentos o el sujeto de la enunciación de los ensayos vincula lo representado en las pinturas, producto de la mirada y la mano de otros, con aquello que ella ve en su tránsito por las ciudades. Particularmente con lo que ve a través de las ventanillas de un ómnibus, como sucede en "Una historia de amor" (Historia de una mujer...), o dentro de un vagón de tren en "Vialidad" (Saña). Vagón y ventanillas que se presentan como dispositivos para encuadrar la mirada.

Lo que se observa en un cuento como "Una historia de amor" o en un ensayo como "Vialidad" es que la autora/narradora traza un continuum entre lo que ve en el museo y lo que ve a través de las ventanillas, en el caso del primero, o dentro del vagón del metro, en el segundo. No se trata de una semejanza entre la materia representada en los cuadros y en las escenas de la vida cotidiana que ella observa, sino que mira los cuadros de Turner como si estuviese mirando por la ventanilla y, cuando se refiere a lo que ve por la ventanilla dice que ve "pasar cuadros". Es así que no sólo no hay una jerarquización entre vida y arte o entre cultura y vida sino que ambos forman parte de la misma materia: la pintura agudiza la mirada sobre la vida pero también elementos tan banales o rutinarios como un ómnibus o un tren urbano se convierten en dispositivos para aguzar la mirada, el espectáculo de la vida. Algo que Nora García nos deja escuchar cuando afirma: "[...] contemplo el panorama; por mi relato van pasando los personajes de la calle o las novelas, los cuadros de 
los museos..." (Glantz, 2007, p. 99). Una frase que me recuerda -aunque suene anacrónico- el verso de Darío en "La página blanca", cuando el poeta ve el desfile de imágenes como "las figuras en un panorama". Imágenes mentales que en el instante en que desfilan ante sus ojos se convierten en materia del poema que está escribiendo, son ese poema. Del mismo modo el cuento o el ensayo de Glantz son la puesta en palabras de las imágenes que ve desfilar ahora, en el momento de la escritura, a través de la ventanilla, el vagón, o la memoria. Quiero decir que las imágenes son el cuento, así como en Darío son el poema.

Como vimos en la cita que transcribí en las primeras páginas del texto, las operaciones que ese sujeto de la enunciación lleva a cabo exceden la mirada y la interpretación y se multiplican en una serie de especulaciones de índole diversa. Entre ellas, el armado de una tradición en la cual ubicar a sus pintores predilectos ocupa un lugar central. Es así que Spencer hace posible la concepción del cuerpo en Bacon y en Lucien Freud como dijimos-, pero también que Bacon es impensable sin el Picasso de la década del '20 y, de igual modo, sin el retrato de Inocencio X, pintado por Velázquez. Obviamente hay aquí un diálogo entre estos pintores, en el sentido en que uno posibilita al otro, y obviamente también la tradición en que Glantz los inserta no es una tradición ni unívoca ni lineal, sino una tradición que opera a través del desvío y de la destrucción, es decir, una tradición sólo posible porque el modelo se subvierte. Picasso y Velázquez se ven en Bacon, pero se ven devastados, pulverizados, se ven en calidad de restos. Al respecto, en "Espejos cóncavos", uno de los fragmentos/ensayos de Saña, Margo Glantz anota: 
Sea lo que sea, es evidente que cuando pude contemplar detenidamente algunos de sus cuadros [de Bacon], al lado de los de Picasso, en el museo del pintor malagueño en París, comprobé que muchos de los signos distintivos de su genio se encuentran a menudo en los lienzos de Francis Bacon, aunque devastados y en ocasiones como una mera sombra (Glantz, 2010, p. 55).

La mirada especulativa de Glantz no se restringe a reproducir una tradición en la que los propios pintores se reconocen sino que la misma es el resultado de las muchas veces en que el sujeto de la enunciación contempló estas obras en museos y muestras diversas, situaciones que en su caso ponen en entredicho la afirmación de Benjamin acerca de la mal disimulada decepción del público ante el hecho de que en las pinacotecas haya sólo cuadros colgados. Es decir, leemos a un mismo tiempo las afinidades en las que los pintores se reconocen y el relato de la mirada de Glantz, quien detenidamente observa, experimenta e interviene activamente en la articulación de esa tradición. Es ese sujeto quien ve las piunturas de Bacon, pero también los de Picasso y Velázquez y, a partir de ello infiere relaciones y se detiene en detalles que le posibilitan organizar un relato en el que hay un juego entre la mirada y los cuadros que contempla casi como una crítica de arte.

Sin embargo, hay momentos en que esa lógica se quiebra para dar paso a un comentario, como dicho al pasar, que descoloca y desmadra el orden, y en ese punto irrumpe una mirada diferente, asombrada y feroz que postula entre los cuadros un nexo impensable. En "Bañistas", ensayo de Saña, en el que en una indiferenciación de voces entre la de ella, la de Bacon y la del crítico de arte Baldassari se centra en la relación entre Bacon y 
Picasso, Glantz comprueba la influencia del pintor malagueño sobre el inglés y desarrolla una especie de écfrasis interpretativa de los cuadros que representan a las bañistas, en los que observa fundamentalmente dos elementos: la presencia de una llave gigantesca y la plasticidad y fuerza del cuerpo de estas mujeres.

El relato se desarrolla de forma más o menos previsible, pero al final surge un paréntesis en el que Glantz escribe "(las mujeres se venden como ganado)" (Glantz, 2010, p.44). Diría que en ese paréntesis, un procedimiento constitutivo de su prosa, Margo Glantz se inscribe y pone en escena una preocupación de otra índole, la del lugar de la mujer en la historia del arte -y en la historia de la cultura- con lo que abre una hendidura por la que se vislumbra una serie diferente, no ya la de la relación entre ambos pintores sino aquella de la mirada de los hombres sobre las mujeres, la de la reificación de estas últimas.

Si la voz de Glantz irrumpe en el paréntesis produciendo una disrupción que funciona como un alerta, cuando volvemos a pensar en la lógica que rige el armado de esa tradición pictórica, vemos que es la misma a la que recurre para situar los textos de su autoría. Con frecuencia, en los momentos en que vuelve sobre sus propios procedimientos y elecciones, sitúa su narrativa o sus ensayos en la huella de otros escritores. Como sucede en relación a Bacon y sus antecesores, la tradición que arma es aquella que privilegia el fragmento, así como la de escritores que disgregaron y pulverizaron las formas tradicionales de la novela. Tampoco aquí se trata de una tradición narrativa dada de antemano o restringida a los límites de lo nacional, sino en la que entran nombres como David Markson, Georges Perec, 
Roland Barthes, Pascal Quignard o Walter Benjamin, entre otros.

Cuando focalizamos el ámbito de la literatura en castellano, vemos que la recuperación/pulverización de una tradición se da sobre todo a través de un juego de temporalidades, en el que Glantz recupera escritores del siglo de oro español o del barroco americano -en especial, Sor Juana- para dislocarlos de su temporalidad específica y hacer que irrumpan en la contemporaneidad y en un contexto completamente diferente. Así como Picasso o Velázquez están en la obra de Bacon pero devastados, como una "suma de varias destrucciones", el eco del siglo de oro español o del barroco mexicano se lee en la narrativa de Glantz en la recuperación de un sólo verso o de una única frase, con lo que simultáneamente genera una relación de continuidad y pertenencia como de perplejidad y extrañeza.

Podemos pensar, entonces, que más allá de la fascinación o el gusto por el arte, la referencia continua a la pintura en sus textos puede entenderse como una suerte de discurso otro para leer e insistir en su propio texto y en su propia poética. Un dispositivo que le permite leerse, mientras deja entrar las voces de los otros, los otros contemporáneos y los otros del pasado. Es así que en Por breve herida, luego de un fragmento en el que lee la transformación de manchas blancas o adornos en la Infanta Margarita Teresa, pintada por Velázquez, en manchas que se convierten en "la esencia de lo que debería ser la pintura", en Bacon o en Lucien Freud, anota casi enseguida: "¿Borrones y borradores en la escritura?" (Glantz, 2016, p. 170), una pregunta que claramente intersecta las dos series y remite a una 
noción de la que se vale recurrentemente para leer los textos escritos en América durante la Colonia.

Páginas atrás me preguntaba qué le dicen las artes plásticas a esta escritora. Tal vez sería mejor acotar la pregunta e intentar indagar qué le dicen las pinturas de Spencer y de Bacon a libros como Historia de una mujer... y Por breve herida.

Sin pretender agotar el tema, no querría dejar de señalar que Spencer, el pintor central del conjunto de relatos de Historia de una mujer... que tienen como escenario y como objeto de reflexión a Inglaterra, funciona allí como un dispositivo para poder pensar/pintar a este país. Pero creo que no tanto porque lo represente en sus rasgos más conocidos o sobresalientes, no tanto en el sentido de una pintura costumbrista sino, por el contrario, como un pintor que pone en escena una paradoja que recuerda la reflexión de Borges, cuando en uno de sus ensayos sostiene que los escritores representativos de un país son aquellos que se oponen a las características del mismo. Es así que si en cuentos como "Una historia de amor" pero también en "Jarabe de pico" o "English love" los cuerpos ingleses son representados siempre como cuerpos envueltos en una materia aislante que los protege del roce del otro, en las pinturas de Spencer los cuerpos parecen haber perdido todo tipo de compostura y se enciman y enraciman. A propósito, en "El té con leche" comenta:

[...] en ellos [los cuadros de Spencer] la gente tropieza, se enracima, se manosea, han olvidado su condición de ingleses, infringen el estricto código de separación en el que los cuerpos, situados siempre a una distancia milimétrica los 
unos de los otros pueden sólo juntarse cuando las parejas se encuentran en la cama (Glantz, 2005, p. 54).

Por su parte, como ya señalamos, Bacon es el pintor fundamental para el andamiaje de Por breve herida. Si ambos convergen en una concepción del arte como una suma de devastaciones, como lo que pulveriza y se pulveriza, disgrega y se disgrega, pienso que buena parte de la fascinación que el pintor ejerce sobre esta escritora se fundamenta también en una concepción similar del lugar que el cuerpo ocupa en la obra de arte. Específicamente, en que tanto para uno como para la otra retratar el cuerpo -hablar sobre éste o pintarlo- constituye "una forma de conocimiento, de indagación" (Chirbes, 2002, p. 57), tal como sostiene Rafael Chirbes cuando habla de la representación pulverizada del mismo en las pinturas del inglés. Pienso que los dos, pintor y escritora, apuestan a reestablecer el vínculo entre el artista y el cuerpo, entendido como materialidad, como aquello que constituye "la sustancia básica de la vida" (Chirbes, 2002, p. 59). 


\section{Referencias Bibliográficas}

Chirbes, R. (2002). "La resurrección de la carne”. R. Chirbes. El novelista perplejo. Barcelona: Anagrama, pp. 48-59.

Garramuño, F. (2015) Mundos en común. Ensayos sobre la inespecifidad del arte. Buenos Aires: FCE.

Glantz, M. (2005). Historia de una mujer que caminó por la vida con zapatos de diseñador. Barcelona: Anagrama.

(2010). Saña. Buenos Aires: Eterna Cadencia.

(2016). Por breve herida. México: Sexto Piso. 